Journal of the

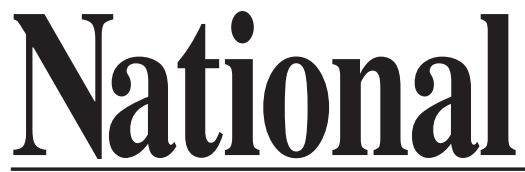

Academy or

Forensic
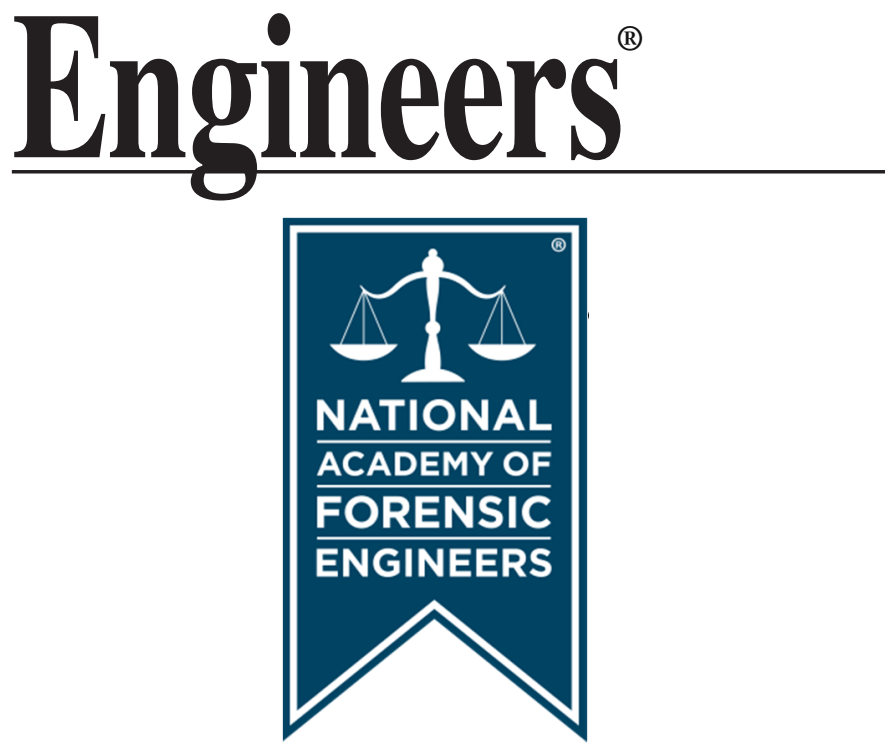

http://www.nafe.org

ISSN: 2379-3252

Vol. XXIII No. 2 December 2006 


\title{
Forensic Engineering Analysis of a Car vs. Car vs. Pedestrian Accident
}

by Jeffrey D. Armstrong, P.E. (644S)

\begin{abstract}
This paper summarizes the forensic engineering analysis and reconstruction of a nighttime vehicle crash. The crash occurred on the inside shoulder of a divided interstate highway separated by a concrete barrier. A driver had stopped his vehicle on the inside shoulder of the westbound section of the highway, presumably due to car troubles. His car was struck in the rear by another vehicle. When emergency personnel arrived at the scene, the owner of the disabled vehicle was found deceased on the inside lane of the opposing eastbound roadway. As the crash was being investigated, a vehicle returned to the scene where the driver indicated that he thought he had run over something as he was traveling eastbound on the freeway. The forensic engineer was retained to reconstruct the accident, and to determine how the driver of the disabled vehicle came to be in the opposing roadway. The reconstruction involved photogrammetry, momentum analysis, crush energy analysis, proper use of pedestrian throw formulae, and a forensic analysis of evidence on the disabled vehicle.
\end{abstract}

\section{Introduction}

The engineer was contacted by the State Attorney's office to prepare a forensic engineering reconstruction of a nighttime vehicle crash that was the subject of a DUI Homicide investigation. An intoxicated driver struck a disabled vehicle which was parked on the shoulder of the roadway. The crash resulted in the death of the owner of the disabled vehicle who was standing in front of his car when it was struck from behind. The forensic engineering reconstruction of the crash calculated the speed of the striking vehicle, analyzed the trajectory of the owner of the disabled vehicle during the crash, and determined that it was indeed the actions of the defendant driver that caused the fatality.

\section{Accident Location}

The crash occurred in the westbound lanes of an Interstate freeway. The freeway has four (4) 12-foot lanes in each direction, with ten-foot shoulders on each side of the roadway. The freeway is located on a causeway (filled section) between a bridge and the main land. There are guardrails adjacent to the outside shoulder. Behind the guardrails the causeway has a 4:1 slope down to the water. The westbound roadway surface is three to four ( 3 to 4 ) feet higher than the eastbound 
roadway. There is a New Jersey barrier adjacent to the inside shoulder of the westbound roadway, with a retaining wall adjacent to the inside shoulder of the eastbound roadway. The roadway is well lit with numerous overhead street lights.

\section{Description of the Accident}

The driver of a 1994 Chevrolet Beretta two-door coupe stopped his car on the inside shoulder of the Interstate highway when it became disabled. He had put his hood up, and was standing in front of his car. While he was standing in front of his car, it was struck from behind by a 1993 Lexus GS-300 four-door sedan. The Beretta was accelerated forward, striking the owner as he stood in front of the car. With the hood of his vehicle up, and him standing in front of it when it was struck, the owner of the car was thrown onto the engine compartment of his accelerating vehicle. His car was struck on the right (passenger side) half of the rear bumper which caused his car to rotate counterclockwise. The left-front corner of his car struck the New Jersey barrier, the car "rode up" the side of the barrier causing the car to roll onto its right (passenger) side. It came to rest on its right side on the inside shoulder. When his vehicle struck the barrier, the owner was thrown from the engine compartment, over the New Jersey barrier, and onto the opposing roadway lanes where a pool of blood marked his rest position. Shortly after coming to rest in the inside lane of the opposing (eastbound) roadway, he was run over by a 1995 Pontiac Grand Prix SE twodoor coupe, dragged in an easterly direction to the point where his deceased body was found by the responding police officers. After the collision, the Lexus rotated counterclockwise, coming to rest in the two inside lanes.

Using the photographs and measurements taken by the investigating police officers, aerial photographs, and roadway plans, a scale diagram was prepared by the engineer for use in analysis and to illustrate the accident scene as it was found by the police. The diagram illustrating the accident scene is shown in Figure 1.

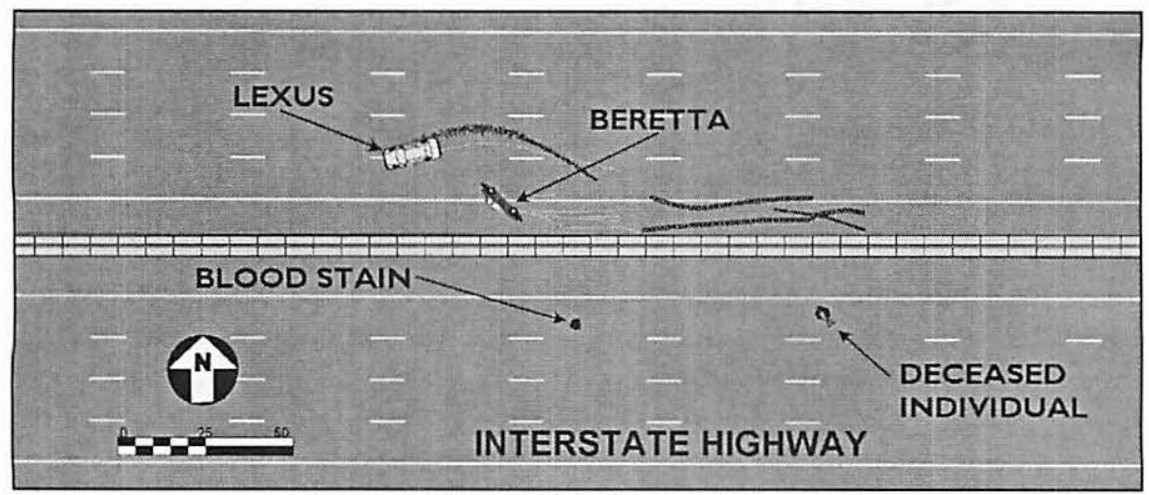

Figure 1 Accident scene diagram. 


\section{Defense Theory}

The defense presented a theory that the deceased vehicle owner was not standing in front of his vehicle when it was struck by the defendant's vehicle. They retained the services of a non-engineer accident reconstructionist to present their theory. They proposed that he had climbed over the New Jersey barrier and jumped down to the lower opposing roadway, and was walking west toward town in the eastbound lanes when he was struck by a "phantom" vehicle, and then run over by the Pontiac Grand Prix. Their theory proposed that since he was not in front of his vehicle when it was struck, that the defendant was not responsible for his death. Some of the reasons presented by the defense expert to explain why the deceased vehicle owner could not have been struck by his own vehicle included the following:

- If the vehicle had struck its owner at the calculated post-collision speed, it would have left a crush zone approximately 12 inches deep and 18 inches wide.

- The energy transfer between the victim and his vehicle at impact would have been the same as swinging a 1,000 pound steel ball from a pendulum which was released from a height of three feet, and having it strike the vehicle.

\section{Evidence Reviewed by the Engineer}

The forensic engineer was retained more than two years after the crash occurred. None of the vehicles were available for inspection, and there was no evidence of the crash remaining at the accident location. The following materials were available for review:

- Traffic Crash Report for the Incident

- Traffic Homicide Report

- Nighttime color photographs of the accident scene taken by the investigating officer

- Daytime color photographs of the three (3) accident vehicles taken by the Investigating officer

- Autopsy Report

\section{Vehicle Description}

The striking vehicle was a 1993 Lexus GS-300 four-door sedan. It received severe contact damage to the front-right corner of the vehicle as shown in Figure 2. This vehicle rotated counterclockwise after the impact and came to rest in the two inside westbound lanes as indicated in Figure 1. 
The victim's vehicle was a 1994 Chevrolet Beretta two-door coupe. It received severe contact damage to the right rear portion of the car as shown in Figure 3. It also received damage to the left-front corner from the impact with the New Jersey barrier as shown in Figure 4. This Figure supports the belief that the hood was up at the time of the collision. The lower portion of the windshield has a long rainbow-shaped crack that matches the shape of the back of the hood as shown in Figure 5 and Figure 6, which suggests that the hood struck the windshield with some force during the collision.

The victim was run over by a 1995 Pontiac Grand Prix SE twodoor coupe after he landed in the opposing roadway. The Grand Prix received damage to the bottom of the front bumper and to the undercarriage. There was no damage to the top of the bumper, grill, hood, windshield, or roof. The damage to the Grand Prix supports the fact that the victim was on the ground when he was run over by the Grand Prix.

\section{Forensic Engineering Reconstruction}

The speed of the striking vehicle was calculated using the principles of conservation of momentum and verified using conservation of energy. The weights of the vehicles were determined using published data for the vehicles. The post-impact distances were determined using measurements taken by the police investigators, and using photogram-

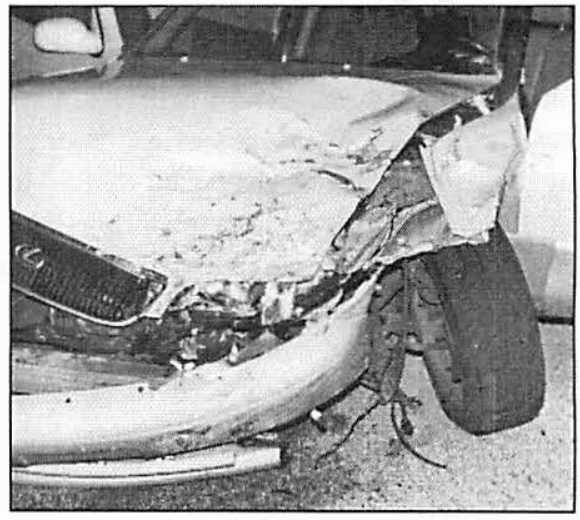

Figure 2

1993 Lexus.

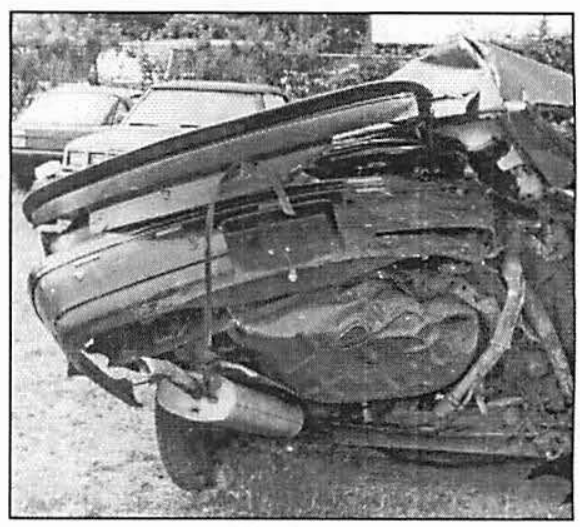

Figure 3

Chevrolet Beretta.

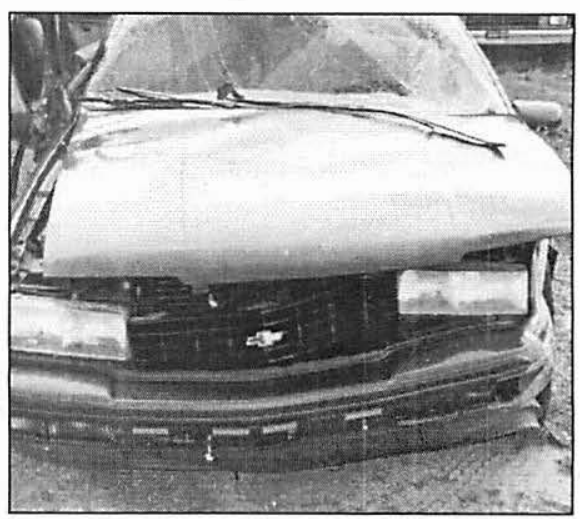

Figure 4

Chevrolet Beretta. 


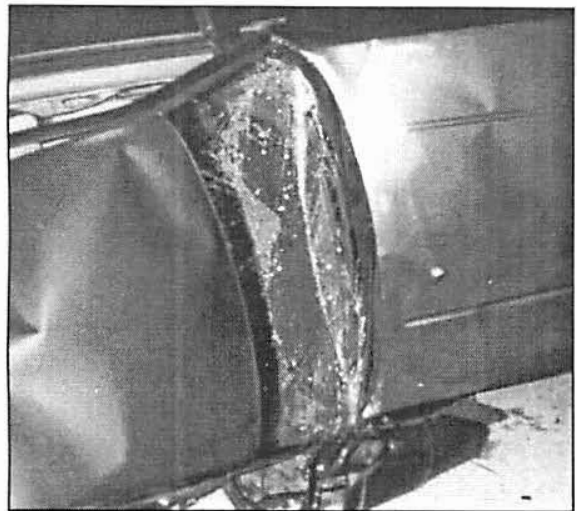

Figure 5

Chevrolet Beretta.

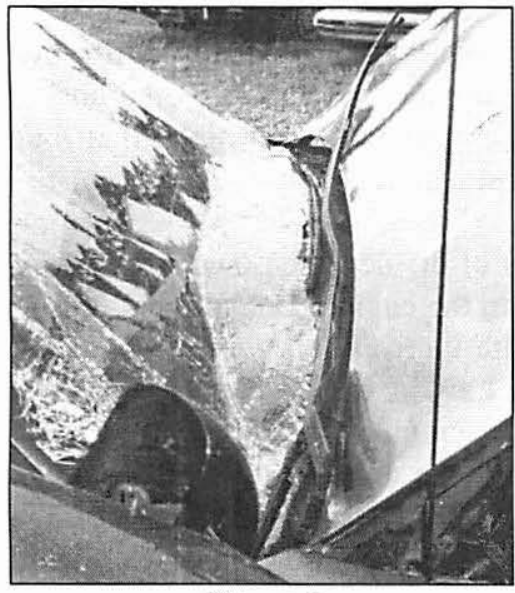

Figure 6

Chevrolet Beretta.

metry analysis of several of the police photographs. A high-low range for deceleration rates (commonly referred to as drag factors) was used for each phase of the crash, based on the rotation of the vehicles, the condition of each of the tires on the vehicles, and the contact surfaces (wheels or car sliding on its side) for the various post-collision phases of the crash. The analysis indicated that the impact speed of the defendant's Lexus was 68 to 73 miles per hour.

An analysis of the post-collision path of the deceased driver's Beretta was performed based on the post-collision tire marks left by his vehicle, and the impact marks that were left on the New Jersey barrier by his vehicle. It was determined that his vehicle struck the barrier at an angle of approximately 25 degrees as shown in Figure 7. The speed of the vehicle as it struck the barrier was 35 to 42 miles per hour.

An analysis of the damage to the deceased driver's vehicle was performed to determine whether there was any evidence that the driver was struck by his

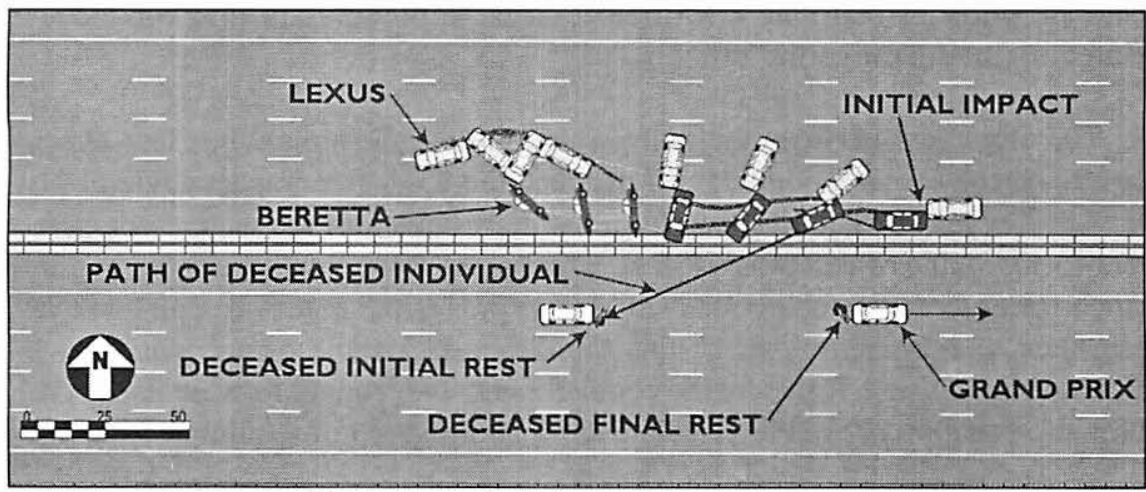

Figure 7 Collision sequence and data. 
vehicle. The photographs of the vehicle showed that the left front corner of his vehicle was crushed due to the impact with the New Jersey barrier, but the left front corner of the hood was not damaged. The top of the hood on this vehicle was lower than the top of the New Jersey barrier, indicating that the hood was up at the time of the collision. If the hood had been down, the leftfront corner would have been crushed from the impact with the barrier similar to the left-front fender. There was a break line near the base of the windshield that indicated that the hood had struck the windshield with a substantial force. This was due to the owner being carried onto the engine compartment, striking the under-side of the hood, which was then pushed forcefully into the windshield. The photographs of the vehicle showed a "rippling" damage pattern, as though the hood had been struck from the underside by a soft, heavy object. The only "soft, heavy object" found at the accident scene was the deceased vehicle owner. Finally, a photograph of the hood latch area showed a fabric print on the engine compartment area that matched the weave pattern in the deceased owner's denim jeans. With the break pattern on the windshield, the unique damage pattern across the hood, and the fabric print on the engine compartment, it was determined that the owner of the Beretta was indeed struck by his vehicle.

An analysis of the post impact trajectory of the deceased owner was performed. After the car's owner was carried onto the engine compartment of his car, the car struck the New Jersey barrier with its front left corner, changing the vehicle's speed and direction. Newton's Law of Inertia dictates that the owner will maintain his initial speed and direction unless acted upon by some external force. This inertia caused him to continue on his path while the car changed its path, and he was thrown over the barrier and into the opposing roadway. Two components of his post impact motion were his movement through the air from the engine compartment of his vehicle to the roadway surface of the opposing lanes, and his sliding from his landing point to a point of rest. The point of rest was identified by a large blood stain that was documented by the investigating officers.

The alignment between the point where the vehicle struck the New Jersey barrier and the owner's point of rest matched the 25-degree impact angle of his car with the barrier. The distance from his departure from the engine compartment to his point of rest was 78 feet. The height differential from the engine compartment to the opposing roadway surface was 6 to 8 feet. A calculation was performed to estimate the speed that the deceased vehicle owner would have been traveling as he left the engine compartment. Two equations were used. The following equation is used to calculate the forward speed of a falling object: 


$$
V_{a}=d a \sqrt{\frac{g}{2\left(d_{a} G-h\right)}}
$$

Where $v_{\mathrm{a}}=$ Initial velocity $(\mathrm{ft} / \mathrm{sec})$

$\mathrm{d}_{\mathrm{a}}=$ Horizontal distance traveled through the air during fall (feet)

$\mathrm{g}=$ Gravity $\left(32.2 \mathrm{ft} / \mathrm{sec}^{2}\right)$

$\mathrm{G}=$ Grade (Percent)

$\mathrm{h}=$ Height of fall (feet)

Since this is based on the motion of a falling object, the height (h) will always be negative. A positive value should be used for gravity ( $g$ ) since a falling object will accelerate rather than decelerate. Rearranging the terms to solve for distance, with the grade at the area of the accident being $0 \%$, we used the following equation:

$$
d_{a}=\frac{V_{a}}{\sqrt{\frac{g}{-2 h}}}
$$

To consider the distance that the driver traveled while sliding on the ground from his point of landing to his point of rest, we used the following:

$$
d_{s}=\frac{v_{s}^{2}}{2 a}
$$

Where $\mathrm{d}_{\mathrm{s}}=$ Distance traveled while sliding (feet)

$v_{\mathrm{s}}=$ Velocity at beginning of sliding (feet)

$\mathrm{a}=$ deceleration rate while sliding $\left(\mathrm{ft} / \mathrm{sec}^{2}\right)$

Note that $v_{\mathrm{a}}$ and $v_{\mathrm{s}}$ in equation (1) and equation (3) should be the same speed, as the change in horizontal speed during the falling phase is negligible. Also note that the takeoff angle associated with the owner's departure from his engine compartment is zero degrees $\left(0^{\circ}\right)$. He would have left the engine compartment with an initial direction horizontal with the ground.

Equation (2) and Equation (3) were added together, with their combined distances being the total distance from his departure from the engine compartment to his final rest location. 


$$
D=d_{a}+d_{s}
$$

Therefore

$$
D=\frac{v_{a}}{\sqrt{\frac{g}{-2 h}}}+\frac{v_{s}^{2}}{2 a}
$$

Where $\mathrm{D}=$ Total distance during fall and sliding (feet)

And

$$
v_{\mathrm{a}}=v_{\mathrm{s}}
$$

The following values, or ranges of values were input into the equation:

$$
\begin{aligned}
& D=78 \text { feet } \\
& g=32.2 \mathrm{feet} / \mathrm{sec}^{2} \\
& \mathrm{~h}=-6 \text { feet to }-8 \text { feet } \\
& a=16.1 \mathrm{ft} / \mathrm{sec}^{2} \text { to } 32.2 \mathrm{ft} / \mathrm{sec}^{2}
\end{aligned}
$$

The second degree polynomial equation was solved for velocity using the quadratic formula. This analysis indicated that the deceased vehicle owner's velocity as he left the engine compartment was 27 to 37 miles per hour. Considering that he would lose some velocity as he came off the engine compartment, this is consistent with the vehicle's velocity of 35 to $42 \mathrm{mph}$ when it struck the barrier.

\section{Keys to Forensic Engineering Analysis}

The qualitative analysis of the photographs of the accident scene and the accident vehicles was a critical part of the forensic engineering analysis. The qualitative analysis led to the determination that the hood of the disabled vehicle was up at the time of the crash, and that the underside of the hood was struck by the vehicle's owner as he was carried onto the engine compartment. The presence of a fabric print matching the owner's denim jeans indicated that he had been on the engine compartment. The quantitative analysis demonstrated the consistency between the vehicles' speeds, the impact velocity, the angle at which the disabled vehicle struck the barrier, and the trajectory and rest position of the vehicle's owner. 


\section{Forensic Engineering Analysis of Defense Theory}

The defense presented a theory that the defendant did not cause the death of the victim because he was not standing in front of his vehicle when it was struck from behind. Their claim was that he had climbed over the wall and was walking toward town when he was struck by a phantom vehicle prior to being run over by the Grand Prix. The forensic evidence on the victim's vehicle, including the damage pattern on the hood, the breakage of the windshield, and the fabric print on the engine compartment clearly demonstrated that the victim had indeed been struck by his vehicle.

The defense claimed that if his vehicle had struck him at the indicated postcollision speed, that the impact between the vehicle and its owner would have left a crush zone on the bumper approximately 12 inches deep and 18 inches wide. This was an improper application of the principle of conservation of energy. This application failed to recognize that the only forces that needed to be overcome to carry the victim onto the engine compartment were the friction forces between his shoes and the ground, and the strength of the bones in his lower leg (shin). Both legs were broken at the approximate height of the bumper. Video tape of numerous crash tests was reviewed, without a single incident of vehicle damage as described by the defense.

The defense also claimed that if the victim had struck the under-side of his hood during the collision, the energy transfer would be the same as if you were to swing a 1,000 pound steel ball from a pendulum which was released from a height of three feet. While it is true that this would result in a similar amount of kinetic energy transfer, one would certainly not expect the same damage pattern from a steel ball as from a human body.

If the victim had been struck by a phantom vehicle prior to being run over by the Grand Prix, it is reasonable to believe that under light traffic conditions that the vehicle would have been traveling near the posted speed of 70 miles per hour. Such an impact would certainly cause major damage to the vehicle, perhaps rendering it undriveable due to severe windshield damage. There may also have been vehicle debris left at the accident scene. However, the defense was never able to present any evidence of such a damaged vehicle, and the investigating police officers did not identify any debris from another vehicle.

\section{Opinions and Conclusions}

The forensic engineering reconstruction of this incident resulted in the following opinions and conclusions:

- The pre-collision velocity of the striking vehicle was 68 to 73 miles per hour. 
- The disabled vehicle had its hood up at the time of impact.

- The disabled vehicle struck its owner who was standing in front of his vehicle at the time of the accident.

- The vehicle owner was carried onto the engine compartment of his vehicle, striking the under-side of the hood, which was up. This pushed the hood back into the windshield. The owner was carried on the engine compartment until his vehicle struck the concrete barrier.

- The disabled vehicle struck the barrier at a velocity of 35 to 42 miles per hour.

- After his vehicle struck the barrier, the deceased owner left the engine compartment with a velocity of 27 to 37 miles per hour.

- The owner was thrown over the barrier and into the opposing roadway after his car struck the barrier.

- The victim's landing location is consistent with the velocity and angle of impact of his car with the barrier.

- Physical evidence, including a well-defined fabric print showed that the vehicle owner had been on the engine compartment.

The engineering reconstruction of this accident required both a creative qualitative analysis of the physical evidence, and a thorough and comprehensive engineering analysis of the crash. This combination of the qualitative and quantitative analyses clearly demonstrated that the defendant driver of the Lexus was responsible for the death of the victim.

The case went to trial where the defendant was tried for DUI Manslaughter. The author provided expert testimony on behalf of the prosecution based on the described engineering analysis. The jury found the defendant guilty. State law calls for a sentence of 10.4 to 15 years. The judge sentenced the defendant to 13 years in prison. It is believed that the defendant's prior DUI convictions, along with two additional DUI arrests while out on bail awaiting the trial in this case, contributed to the length of the sentence. 